\title{
CINEMA EDUCATIVO DO FASCISMO E DO ESTADO NOVO EM COMPARAÇÃO'
}

\author{
CINEMA EDUCATIONAL OF FASCISM AND \\ THE NEW STATE IN COMPARISON
}

\begin{abstract}
Cristina Souza da Rosa*
Resumo: Durante os anos de 1920 foram protagonizadas intensas discussões sobre o uso do cinema e as conclusões a que chegaram intelectuais, professores, médicos, católicos e advogados era que o cinema deveria ser utilizado para fins educativos. Tais debates levaram governos autoritários e capitalistas do mundo a investirem na produção de filmes educativos, com o fim de levar valores e ideias a jovens e crianças. $\mathrm{O}$ presente artigo faz uma comparação entre os institutos de cinema educativos do Fascismo e do Estado Novo com o objetivo de encontrar semelhanças e diferenças entre si.

Palavras-chave: Fascismo, Estado Novo. INCE. LUCE. Cinema educativo.

Abstract: During the 1920s the main characters were intense discussions on the use of cinema and the conclusion arrived by intellectuals, teachers, doctors, lawyers and Catholics was that the film should be used for educational purposes. These discussions led authoritarian governments and capitalists in the world to invest in the production of educational films for the purpose of carrying values and ideas to young and children. This article provides a comparison between the educational film institutes of Fascism and the New State in order to find similarities and differences.
\end{abstract}

Keywords: Fascism. New State. INCE. LUCE. Educational cinema.

\footnotetext{
* Pós-doutoranda no Centre d'Investigación Film-Historia da Universitat de Barcelona.

E-mail: crisrosablu@gmail.com
} 


\section{INTRODUÇÃO}

Em maio de 1936, o presidente Getúlio Vargas autorizou a organização do Instituto Nacional de Cinema Educativo (INCE), sob a jurisdição do Ministério da Educação e Saúde. O INCE nascia com a missão de

Orientar a utilização da cinematografia na obra de educação nacional em todas as suas modalidades e incentivar a produção, facilitar a circulação e intensificar a exibição em todo o território nacional, de filmes educativos ou culturais. ${ }^{2}$

Para o comando do instituto, Capanema convocou Edgar Roquette-Pinto, professor, médico, legista, presidente da comissão de censura cinematográfica e diretor do Museu Nacional. Este, por sua vez, solicitou a contratação de Humberto Mauro, cineasta mineiro, para o cargo de técnico cinematográfico, que aceitou o convite com "a certeza de estar colaborando com uma obra de criação, pois o cinema educativo no Brasil era zero". ${ }^{3}$ Com efeito, até aquele momento, nada parecido havia sido organizado no Brasil, o que caracterizava o projeto como algo novo. Diante deste fato, Capanema resolveu buscar informações sobre as experiências europeias, onde, desde a década de 1920, já existiam institutos de cinema educativo que produziam e distribuíam filmes sob a tutela do Estado.

A tarefa de recolhimento de dados coube a duas pessoas, Edgar Roquette-Pinto e, ao estudante de Direito Roberto Assumpção de Araújo, que participaria, como nadador, nas Olimpíadas de 1936, em Berlim. ${ }^{4}$ O jovem atleta deveria aproveitar seus dias de folga no continente europeu para visitar e coletar informações sobre os institutos de cinema da Alemanha, da França e da Bélgica. De volta ao Brasil, o estudante encaminhou ao diretor do INCE e ao ministro da Educação um relatório, cujo conteúdo informava sobre os institutos de cinema visitados, relatava possíveis intercâmbios e sugeria o contato do INCE com seus congêneres do velho continente. Na Alemanha, Araújo conseguiu que Reichsstelle Für den Unterrichtsfilm, por intermédio de seus diretores, apoiasse a iniciativa brasileira, oferecendo-se a colaborar com a organização do INCE. O Musée Pédagogique, da França, dirigido por Jean Painlevè, se propôs a enviar diversos filmes ao Brasil. No entanto, o relatório apontava a importância de manter contato com o Instituto Internacional de Cinema Educativo (IICE), pertencente à Liga das Nações e mantido pelo governo fascista.

No mesmo ano, Roquette-Pinto é enviado à Itália fascista com missão parecida à do estudante de Direito. Desta vez, o foco era os dois institutos de cinema organizados e mantidos pelo governo de Mussolini: L' Unione di 
Cinema Educativo, também conhecido como Instituto Nacional LUCE, e o Instituto Internacional de Cinema Educativo (IICE). Em Roma, cidade sede das duas entidades, Roquette-Pinto circulou, observou o funcionamento e a organização de ambos os institutos, assistiu filmes e documentários e conversou com os especialistas italianos. ${ }^{5}$

No que tange ao cinema educativo, estes não foram os primeiros contatos estabelecidos com a Itália. Em 1929, por exemplo, Roquette-Pinto escreveu a Luciano De Feo, diretor do IICE, oferecendo-se para colaborar na Revista Internacional de Cinema Educativo (RICE), publicada pelo Instituto Internacional de Cinema Educativo. De Feo, por sua vez, mostrou-se interessado na colaboração do colega brasileiro em carta resposta. ${ }^{6}$ Em 1930, Jonathas Serrano, professor do Colégio Pedro II e autor do livro Cinema e Educação, escreveu um artigo na RICE sobre o desenvolvimento do cinema educativo no Brasil. Nele, o autor fazia referência especial à $1^{\text {a }}$ Exposição Cinematográfica Educativa, que ocorreu no Rio de Janeiro, em 1929, e que contou com a participação da embaixada italiana através do envio de um projetor do LUCE e cópias do primeiro número da RICE. Em 1934, Luiz Simões Lopes, enviado a Europa por Getúlio Vargas, depois de conhecer o que se fazia em relação ao cinema na Itália de Mussolini, escreve a José Roberto de Macedo, encarregado de negócios da embaixada brasileira em Roma, pedindo-lhe que reunisse toda a legislação sobre cinema, que preparasse uma lei geral sobre o cinema no Brasil e outra sobre filmes educativos e, por último, sugeriu que se criasse em nosso país um "órgão semelhante à LUCE, destinado principalmente à produção e controle de filmes educativos, de filmes científicos, para o ensino nos diversos graus [...]". 7 Um ano depois, José Roberto de Macedo redigiu um projeto de lei para regulamentar a censura cinematográfica, "elaborado de acordo com o Prof. Dr. Luciano De Feo". ${ }^{8}$

As referências ao LUCE e ao IICE também eram vistas nas revistas brasileiras especializadas em cinema. A Revista Cinearte havia encabeçado uma campanha pela valorização do cinema nacional e também pela implementação do cinema educativo. Em suas páginas clamava pela intervenção estatal no campo cinematográfico através de leis e incentivos apropriados, que estimulassem a produção e a distribuição dos filmes nacionais. Em meio à campanha, as ações do governo fascista na área do cinema de entretenimento e de educação, apareciam no magazine como exemplos a serem seguidos. Ao governo de Getúlio Vargas não cansavam de aconselhar que se espelhasse nas atitudes de Mussolini, considerado um benfeitor do cinema.

Que motivos levaram os brasileiros a buscarem na Itália fascista as informações necessárias para implementar o cinema educativo no Brasil? Entender o porquê desta aproximação nos ajuda a compreender melhor o 
processo de organização e formação do INCE e a relação do Estado Novo com o cenário político internacional da época.

Mussolini foi o primeiro chefe de Estado de um país capitalista a organizar, a sustentar e a incluir um instituto de cinema na estrutura administrativa de governo. ${ }^{9}$ O Instituto Nacional LUCE se tornou órgão oficial fascista em 1925, depois que Mussolini comprovou a eficiência do uso do cinema como veículo de informação, educação e propaganda. A partir desta data o instituto concentrou em suas mãos a produção cinematográfica e fotográfica do governo, construindo, por via das imagens, uma nova visão de mundo.

Em 1928, os fascistas ofereceram-se para organizar dentro da Liga das Nações o Instituto Internacional de Cinema Educativo (IICE), cuja função seria a de reunir o maior número de informações sobre o cinema educativo, fazer circular estas informações entre as nações interessadas e arquivar as películas educativas produzidas nos quatro continentes em uma cinemateca. A ideia do instituto foi acolhida com bastante entusiasmo pelos grupos que consideravam fundamental regulamentar o cinema de modo a transformá-lo em um instrumento de educação. No entanto, a criação do IICE não foi marcada somente pela alegria. Países como França encaravam a organização do instituto com desconfiança, já que o mesmo ficou sob o patrocínio e administração italiana. Por outro lado, se olharmos a ação em um contexto macro, os feitos fascistas fizeram com que a comunidade internacional reconhecesse Mussolini como benfeitor do cinema educativo. Tal reconhecimento foi confirmado em 1927, durante $1^{\circ}$ Conferência Europeia de Filme Educativo, quando o Instituto Nacional LUCE foi citado nas resoluções finais como modelo a ser seguido por todas as nações que desejassem organizar institutos desse tipo. Neste dia, Luciano De Feo escreveu a Mussolini informando-lhe que o LUCE se tornara uma "luz para todos". ${ }^{10}$ A partir de então, os fascistas, comandados por De Feo, ganharam a frente nas discussões sobre cinema educativo, passando a Alemanha e a França, e conquistaram a supremacia dos debates em importantes revistas de cinema, onde circulavam suas ideias.

Neste sentido, os institutos de cinema atuavam como instrumentos da política externa do Fascismo, que almejava ser visto de forma positiva e descolado de uma imagem autoritária. Neste afã, o Instituto Nacional LUCE e o Instituto Internacional de Cinema Educativo foram utilizados como veículos de propaganda. A missão diplomática encabeça por eles era a de divulgar aos quatro cantos as benfeitorias de Mussolini no campo da cultura e do cinema. Desta maneira, procuravam transformar os olhares das outras nações, fazendo com que diminuísse a desconfiança destas para com o Fascismo. Portanto, os institutos estavam abertos aos contatos vindos do estrangeiro, o que facilitava o intercâmbio de informação entre o Brasil e a Itália, seja por meio de visitas, de colaboração ou de envio de material. 
A estrutura administrativa e ideológica do Estado Fascista, de caráter nacionalista e intervencionista, atraía o olhar dos intelectuais, professores e jornalistas brasileiros que defendiam a intervenção do Estado como garantia do desenvolvimento e da proteção a indústria cinematográfica nacional e educativa. Assim, as ações protecionistas de Mussolini eram apresentadas como exemplos a Getúlio Vargas. Somado a isto, acrescentamos a política desenvolvida pelo próprio governo de Vargas, que buscava, no exterior, modelos de instituições autoritárias e nacionais. O resultado disto foi a criação, no Brasil, de institutos, departamentos e leis inspirados em órgãos e leis fascistas e/ou nazistas. Vale ressaltar que esse procedimento não gerou cópia e sim, o que chamo, de um processo de antropofagia política e social comum ao período histórico em que estava situado o governo Vargas. O conceito de transferência, de Michel Espagne, nos ajuda a compreender melhor este processo:

Transferência compreende as mudanças que se realizam através da transição de conceitos, normas, imagens e representações de uma cultura para outra. Estas transições podem resultar de migrações, mas também de encontros e de leitura de textos de outra cultura. ${ }^{11}$

Espagne argumenta que cada nação se constitui, não somente de suas próprias tradições, como também - e sempre - de uma parte essencial, através das transferências de outras nações. Sendo assim, é importante valorizar as transferências para compreender a organização do cinema educativo e de propaganda no Brasil, bem como, do Estado Novo. Desta forma, nos interessa analisar o papel político do Instituto Nacional de Cinema Educativo (INCE) em comparação com o Instituto Nacional LUCE. Para isto, empregamos a metodologia da história comparada, em seu sentido clássico, onde buscamos discutir as diferenças e semelhanças entre os dois institutos, focando tanto no âmbito da política dos países aos quais pertenciam como na organização e no funcionamento interno de cada instituto.

\section{LUCE E INCE: UM OLHAR COMPARATIVO}

Em 1924, localizado em um modesto edifício do Lungotevere Castello, nasceu o Sindacato Istruzione Cinematografica (S.I.C.), cujo objetivo era produzir filmes educativos e científicos para as escolas. A sociedade foi organizada e fundada por Luciano De Feo, advogado e ex-jornalista, que acreditava que o cinema poderia ir além da função de entretenimento. Fazia parte do conselho administrativo o fascista Civelli, ex-intendente da "Marcha 
sobre Roma", e recém empossado Chefe Geral de Milícia. Logo de inicio, o SIC se une ao jornalista Guelfo Civinini e embarca na produção do filme $A$ ethiopia, um longa-metragem sobre a expedição à Etiópia.

O investimento inicial do Sindacato era de 1000 liras, considerado pouco para uma sociedade que pretendia investir na produção de cinema para escolas. A dificuldade de fazer o projeto decolar, levou Luciano De Feo a procurar seu ex-colega de jornal Perseveranza, Giacomo Paulucci di Calboli, então chefe de gabinete de Mussolini no Ministério do Exterior, para tentar se aproximar do governo fascista. A grandeza do projeto pedida um parceiro com poder econômico e também político, que fosse capaz de criar mecanismos de inserção do projeto nas escolas. Calboli, por outro lado, sabia que Mussolini buscava criar uma imagem positiva de si mesmo e de seu governo, ao mesmo tempo, em que tentava reforçar seu poder, e, que por isto, o cinema poderia ser um interessante aliado no processo de conquista do consenso popular. Desta maneira, o chefe de gabinete de Mussolini sugeriu ao ex-colega que o Sindacato não se dedicasse apenas a produção de filme educativos, mas também de propaganda. O encontro aconteceu em abril de 1924 e em julho, do mesmo ano, os cinegrafistas do S.I.C se dirigiram ao Palácio Chigi, sede da Presidência do Conselho, para filmar Mussolini trabalhando em seu escritório, originando o curta-metragem Onde se trabalha pela grandeza da Itália. No verão de 1924, o curta foi exibido em uma praça pública de Nápoles, de forma gratuita, para uma grande público, junto a outros documentários de caráter educativocientífico feitos pelo S.I.C, como parte das atividades da Mostra de Emigração que acontecia na cidade. ${ }^{12}$ Nesta mesma ocasião, em uma sessão privada, Mussolini foi apresentado aos filmes e saiu da projeção bastante entusiasmado com o que viu. Segundo Ernesto Lauro, Mussolini viu de imediato o potencial do cinema como meio educativo, de propaganda e construção do consenso. ${ }^{13}$

Ao voltar de Nápoles, o chefe de governo trocou o nome do Sindacato para L'Unione Cinematografica Educativa, pois o primeiro lhe parecia muito modesto em relação aos planos que tinha para o instituto. As iniciais do novo nome formavam a palavra LUCE, que em italiano significa luz. Uma luz para todos era o que pretendia Mussolini que fosse o novo instituto fascista, ou seja, que fosse um exemplo para todos os que quisessem organizar um instituto de cinema. Desta forma, o LUCE assumia a função de fazer a propaganda externa do Fascismo uma vez que servia de referência para as discussões sobre os usos do cinema educativo e sobre a institucionalização do mesmo. Durante a década de 1920 e 1930 intelectuais do mundo inteiro discutiam a importância do cinema na formação da personalidade infantil e sobre seus usos pela indústria cinematográfica. Em resumo, estes intelectuais pediam que o cinema fosse regulado, que fosse usado para a educação e que os governos organizassem institutos de cinema educativo. Ao institucionalizar o LUCE, em 
1925, Mussolini passa a ser o primeiro chefe de um governo capitalista a tomar tal atitude e isto faz com que os olhos do mundo se voltem para o fascismo e seu novo instituto de cinema. Assim, o LUCE levava ao mundo os feitos do fascismo para com o cinema.

O LUCE não se tornou um órgão oficial de governo de imediato. A principio, manteve a condição de sociedade anônima, com a participação no conselho administrativo de uma série de repartições e organismos públicos. Luciano De Feo ocupou o cargo de diretor geral, Paulucci di Calboli de vicepresidente e o embaixador e senador Giuseppe De Michelis a presidência. O LUCE ficou sob a jurisdição do Ministério do Exterior, onde Mussolini era ministro e Calboli seu chefe-de-gabinete. A incorporação do LUCE no governo fascista foi feita pouco a pouco. Em 14 de julho de 1925, Mussolini solicitou ao ministro da Pública instrução que estudasse a questão do cinema de forma a definir um programa completo de introdução da cinematografia nas escolas médias e primárias da Itália. A outros ministérios solicitou que reconhecessem o LUCE como órgão de governo e que fizessem uso de sua estrutura. Em 5 de novembro de 1925, através do decreto-lei n.1985, se tornou órgão autônomo e paraestatal, passando a ser reconhecido como órgão técnico cinematográfico oficial de todos os ministérios, órgãos e autoridades do governo fascista. O decreto, além de dar nova diretriz ao Instituto, garantia a ele o monopólio sobre a produção cinematográfica educativa e de propaganda do governo fascista. Com isto, o LUCE se tornava um instrumento de conquista do consenso, divulgando através das imagens a cultura italiana eleita pelo fascismo como nacional e levando para a sociedade o projeto nacionalista e imperialista de Mussolini.

Não foi com função diferente do LUCE que o INCE foi organizado em 1936. Como o congênere italiano, o INCE deveria "organizar um plano geral de educação popular, compreendendo a educação física, médico-sanitária, econômica, artística, social e moral, por meio de projeções, quer fixas, quer animadas" ${ }^{14}$, além de produzir filmes educativos e de cultura. Como o LUCE, quase um ano depois de sua organização, em janeiro de 1937, o INCE se torna um órgão oficial do Ministério de Educação e Saúde, através da lei n. 378. Sendo o INCE, até então, o único instituto de cinema do governo Vargas, ele estava habilitado a produzir filmes para outros ministérios e também para autoridades de governo e pessoas que desejassem fazer documentários com o objetivo de apresentar seus estudos ou descobertas em eventos científicos. Até 1939, quando o Departamento de Imprensa e Propaganda (DIP) é criado, o INCE mantém o monopólio da produção de filmes para o governo Vargas. Um dos primeiros filmes produzidos pelo INCE, $O$ dia da Pátria, tem um caráter de propaganda de governo, pois exibe os desfiles organizados pelo ministério da Educação e Saúde no dia 7 de setembro. Em uma perspectiva próxima de Chartier, podemos afirmar que os institutos LUCE e INCE atuariam como um 
espaço de construção de sentido, onde as representações sociais do Fascismo e do Estado Novo eram organizadas em forma de cultura nacional. ${ }^{15} \mathrm{Ou}$ seja, é no interior destes institutos que a cultura nacional se transforma em imagens sendo distribuídas nos cinema para que sejam vistas e incorporadas pela população.

Educação, durante os anos de 1930 e de 1940, nada mais era que "ginástica de sentimento, aquisição de hábitos e costumes de moralidade, de higiene, de sociabilidade, de trabalho e até de vadiação [...]. A instrução dirigese principalmente à inteligência. $\mathrm{O}$ indivíduo pode instruir-se sozinho; mas não pode se educar senão em sociedade ${ }^{2}{ }^{16} \mathrm{O}$ conceito de educação não estava muito longe do que significava propaganda. Para fascistas e estadonovistas propaganda nada mais era que propagação de ideias, valores e conceitos. Isto nos mostra que os conceitos de educação e propaganda estavam muito imbricados um no outro, dificultando, em certo sentido, a distinção entre um filme de propaganda e de educação. A linha que os separava era extremamente tênue. No entanto, no final dos anos de 1930, os fascistas deixaram de utilizar o termo propaganda e o substituíram por cultura popular, pois propaganda implicava em uma relação autoritária entre povo e governo, enquanto cultura popular demonstrava a importância que o povo assumia dentro do governo fascista. Assim, LUCE e INCE não produziam filmes de propaganda e sim de cultura popular, de educação. Tentando resolver o problema entre filmes de propaganda e de educação, Roquette-Pinto criou uma distinção entre os filmes produzidos pelo INCE: “educação popular" e "educação escolar". Os primeiros documentavam acontecimentos, cerimônias e rituais governamentais, $O$ dia da Pátria e $O$ dia da Bandeira são exemplos destes filmes, e eram exibidos em centros operários, agremiações esportivas e sociedades culturais. Os segundos eram exibidos em escolas. Mais do que definir conceitos cinematográficos a distinção tinha a função de classificar, e porque não justificar, uma produção que mostrava a ideologia do Estado Novo e que não se encaixava muito bem no projeto inicial do INCE.

Nos primeiros anos de existência, o INCE foi financiado com a 'taxa cinematográfica para a educação popular' recolhida através da exibição de filmes de entretenimento nos cinemas, depois passou a fazer parte do orçamento do Ministério da Educação e Saúde. O LUCE, no começo, recebia dinheiro dos ministérios e órgãos paraestatais e estatais, depois, com o passar dos anos, foi incrementando seu orçamento com a venda e aluguel dos filmes e dos cinejornais.

Em 1926, foi instaurada na Itália a lei da obrigatoriedade, que determinava que fosse incluído nas sessões de cinema filmes com "objetivos de educação civil, propaganda nacional ou cultura variada". ${ }^{17}$ Segundo documentos da época, a nova lei era um pedido espontâneo dos comerciantes e administradores de cinema, que em assembleia haviam votado a petição. Até que ponto tal lei era 
espontânea, uma vez que a ditadura de Mussolini já estava instaurada e o LUCE estruturado a ponto de produzir filmes para toda a Itália? Na realidade, a lei tinha por objetivo criar um mercado exibidor para o instituto LUCE, garantindo não apenas locais de exibição, mas também um mercado de compra e aluguel de filmes. Por outro lado, a palavra espontaneidade cria uma sensação de consenso entre o governo e os produtores, construindo em torno da palavra e da ação uma harmonia social. No Brasil, através do decreto n.21.240, a lei da obrigatoriedade foi instaurada. Diferente da Itália, tal lei não beneficiava o INCE e, sim, era fruto de um movimento organizado por intelectuais, jornalistas, professores e produtores de cinema, entre eles Roquette-Pinto e Jonathas Serrano, que desejavam valorizar e estimular a indústria nacional. A lei brasileira obrigava que os filmes nacionais fossem incluídos na programação semanal, com isto, garantindo um mercado exibidor. Vale observar que a lei da obrigatoriedade foi instaurada em diversos países durante os anos de 1920 e 1930, fazendo parte de um movimento mundial em prol dos filmes nacionais e de educação. No caso do Brasil, a lei funcionou como uma estratégia de conquista e adesão à medida que o governo, ao aprová-la, conquistou o apoio dos grupos envolvidos no projeto de lei. Sobre a obrigatoriedade, vale observar que a lei, tanto no Brasil como na Itália, foi acompanhada de medidas de repressão nos casos em os cinemas não a cumprissem, isto nos mostra que nem todos estavam dispostos a ceder parte da sessão aos filmes nacionais italianos ou brasileiros.

A lei de 1926 faz com que o LUCE se reorganize internamente criando um departamento comercial com 11 agências e 38 subagências que cuidavam da venda e aluguel dos filmes. O INCE nunca chegou a ter um departamento comercial. A estrutura pequena do instituto fazia com que funções burocráticas ou comerciais ficassem a cargo do diretor. A estrutura de distribuição do instituto brasileiro também era bastante precária; os professores ou interessados, que estavam no Distrito Federal, poderiam retirar os filmes diretamente na sede do INCE e os que estavam em outros estados deveriam solicitar o filme por correio. Roquette-Pinto bem que tentou organizar um sistema de distribuição através de um Serviço de Cinema Escolar que estaria ligado às delegacias regionais de ensino, mas não conseguiu. As cidades da região sudeste do Brasil foram as que mais receberam filmes do INCE entre 1936 e 1942. Em 1938, Roquette-Pinto tenta estabelecer um acordo comercial com a Distribuidora de Filmes Brasileiros (D.F.B.) para que ela se encarregasse de distribuir os filmes do INCE a diferentes cidades e Estados. O LUCE possuía um sistema de distribuição próprio e bastante eficaz, formado por pequenos Luces regionais que se ocupavam de distribuir os filmes nas escolas, centros, associações e cinemas. Quando uma cidade não tinha cinema, o furgão do LUCE, equipado com tela, projetor e pessoal, se dirigia as praças para promover uma exibição pública. Ainda que a distribuição dos filmes do LUCE fosse melhor estruturada 
que a do INCE isto não significa que o primeiro não tenha tido problemas para implementar o cinema educativo na Itália.

A grande dificuldade encontrada pelos dois institutos não era tanto a distribuição e sim a compra dos projetores de $16 \mathrm{~mm}$ pelas escolas. ${ }^{18}$ Tanto no Brasil como na Itália, as escolas tinham dificuldades financeiras para adquirir o equipamento, e isto limitava a atuação dos institutos. No Brasil um projetor de $16 \mathrm{~mm}$ silencioso custava em trono de 300 dólares, enquanto o sonoro custava duas ou três vezes mais, o que fazia com que muitas escolas comprassem apenas o silencioso. Para solucionar o problema do cinema falado, o INCE criou uma série de recursos como, mandar o roteiro para ser lido pelo professor; gravar as falas em disco que seriam escutadas enquanto o filme passava; uso de alto-falantes acoplados ao projetor, tudo para facilitar a difusão do som nas escolas. Roquette-Pinto considerava que desprezar o som era abrir mão de 50\% de sucesso do cinema escolar. Para estimular a compra de projetores pelas escolas brasileiras, Roquette-Pinto estabeleceu que as escolas ou associações que provassem ter um projetor cinematógrafos sonoro de $16 \mathrm{~mm}$, ganhariam uma coleção de filmes educativos sonoros. No entanto, não sabemos até que ponto tal premiação surtiu efeito, pois não há registro, nos documentos do INCE, sobre os resultados obtidos com a promessa. $\mathrm{O}$ fato, é que os projetores em 1944 seguiam tento um custo alto para as escolas, pois, neste ano, uma professora, do interior do Brasil, mandou uma carta a Dona Maria Capanema solicitando cr\$1000,00 para completar o dinheiro necessário para a compra de um projetor. ${ }^{19} \mathrm{Na}$ Itália, em 1926, Mussolini também recebeu uma carta de jovens balilas solicitando que o Duce enviasse à escola certa quantidade de dinheiro para comprar um projetor. Caso o dinheiro fosse enviado e o projetor comprado, o primeiro filme que gostariam de assistir era A Marcha sobre Roma, para ver Mussolini vestido com a camisa negra e entrando triunfante em Roma. ${ }^{20}$

Em 1926, o LUCE organizou a sua primeira cinemateca chamada Agrícola Nacional, cuja função era produzir filmes voltados à agricultura. A criação desta cinemateca estava diretamente relacionada ao projeto de implementação de novas técnicas e sistemas agrícolas, com o fim de tornar a Itália autossuficiente na produção de trigo e de manter o camponês no campo, evitando o êxodo rural. A grande produção desta cinemateca foi o longa-metragem A Batalha do Trigo em que Mussolini aparecia, de dorso nu, ceifando o trigo e servindo de exemplo a todos. Ao longo da existência do LUCE outras cinematecas foram organizadas, sempre relacionadas com algum projeto do governo fascista. O objetivo destas cinematecas, compostas por conselhos administrativos próprios, era o de produzir, distribuir e conservar filmes específicos. A cinemateca de Cultura Nacional, por exemplo, surgiu no momento em que Mussolini começava a estimular as escavações arqueológicas em busca dos traços romanos. O motivo destas escavações era revelar ao povo 
italiano o passado romano e com isto estabelecer um vínculo de continuidade entre o Império Romano e o presente fascista. Por outro lado, ajudava a construir a ideia de que o povo italiano era herdeiro dos romanos. Assim, o mito da Romanitá se consolidava nas muralhas, aquedutos e nos restos arqueológicos do Império Romano.

O projeto inicial do INCE previa a organização de cinematecas, que por fim não foram criadas. O instituto brasileiro não possuía uma seção cinematográfica especial como o Instituto LUCE, que tinha uma seção de filmes científicos comanda por Roberto Omegna. Todo o trabalho de produção, adaptação, redução de película e montagem, estava entregue a uma única equipe liderada por Humberto Mauro. Os filmes educativos escolares e populares, assim como os longas-metragens, eram classificados e catalogados conforme temas e assuntos filmados. Não se tem notícias de que outros ministérios, além do da Educação e Saúde, tenham utilizado a maquinaria cinematográfica do INCE para a produção de filmes. Sabe-se que o Ministério da Agricultura do governo Vargas possuía um Serviço de Informações Agrícolas que produzia filmes. O DIP, quando foi criado em 1939, começou a produzir o cinejornal Brasileiro e os 127 primeiros números foram produzidos pelo estúdio Cinédia, no Rio de Janeiro.

Em 1942, Lorival Fontes, diretor do DIP e simpatizante confesso do Fascismo, tentou incorporar o INCE ao DIP com a intenção de "controle e coordenação efetiva dos planos ministeriais de propaganda" ${ }^{21} \mathrm{O}$ pedido de Lorival Fontes não obteve o resultado esperado, e INCE e DIP seguiram separados exercendo as funções que cabiam a cada um.

O LUCE concentrava todo o serviço de produção de filmes e fotografia do governo Fascista. A partir de 1927, o instituto passou a produzir o noticiário semanal Cinegiornale LUCE sendo o único responsável pela divulgação da informação cinematográfica. Seus funcionários eram os únicos autorizados a fazer imagens cinematográficas e fotográficas de Mussolini e, por sua vez, o LUCE detinha o monopólio sobre a distribuição de fotos de Mussolini, de eventos, de cerimônias e rituais de governo aos jornais e às revistas da Itália. No Fascismo, no campo das imagens, não havia duplicidade de serviços. O INCE chegou a produzir três cinejornais, o primeiro em novembro de 1939 e os outros dois em dezembro do mesmo ano. O mais provável é que tenha deixado de produzi-los quando da criação do DIP, em dezembro de 1939. A partir de 1939, o DIP era o único responsável pela distribuição das fotos oficiais de Getúlio Vargas, no entanto, não tinha o monopólio da imagem do Presidente como tinha o LUCE com relação a Mussolini.

A produção de longas-metragens não era comum aos dois institutos. O LUCE produziu cinco longas, todos relacionados com o Fascismo e a chegada ao poder de Mussolini, enquanto o INCE realizou dois. Dux (1926), 
Decennale (1932), Camicia Nera (1933), Il Cammino degli Eroi (1936), Scipione L'Africano (1937) são os nomes das cinco produções do LUCE. O INCE produziu $O$ descobrimento do Brasil (1937), que começou a ser feito em 1936 pelo Instituto do Cacau da Bahia, e Os Bandeirantes (1940), ambos tratando de temas históricos brasileiros. $O$ dia da Pátria e $O$ dia da bandeira são dois documentários de caráter cívico registrado pelo INCE. Os documentários de caráter cívicos produzidos pelo LUCE são incontáveis e, seguramente, perfazem a maioria dos filmes no catálogo do instituto. Uma olhada geral sobre os filme do LUCE nos indica que os documentários, curtas e médias-metragens, versavam sobre cultura, ciência, arte, personalidades variadas, comemorações nacionais, festas populares, dança, acontecimentos de atualidade, esporte, política, geografia, arqueologia, forças armadas, higiene, medicina, indústria e organizações juvenis. O catálogo do INCE, que era oferecido às escolas, indica as seguintes categorias: medicina, história natural, história do Brasil, música, literatura, ciências sociais, educação física, geografia, literatura, física, tecnologia, química, indústria, jornal e documentário. A última categoria é a mais versátil de todas, agrupando películas com temas oficiais (cerimônias cívicas, feiras, exposições, serviços do Ministério da Educação e Saúde), geográficos (cidades europeias e brasileiras), e esportistas (danças regionais e corridas rústicas).

A partir de 1940, quando Paulucci di Calboli deixa o LUCE para assumir a embaixada da Itália na Espanha, o LUCE muda de fisionomia. Na verdade, esta mudança já estava sendo gestada deste a Guerra da Etiópia (1936), quando o LUCE passou a dedicar-se a produzir filmes e cinejornais sobre a contenda. Pouco a pouco, as produções educativas perdem espaço para os cinejornais, até que deixaram de ser realizadas em 1944. Também com a saída de Calboli, o Ministério da Cultura Popular (MINCULPOP) aumentou sua influência sobre o instituto direcionando a produção para cinejornais e documentários de guerra. Um exemplo desta mudança interna sofrida pelo LUCE foi exposto por Roquette-Pinto, em 1942, em um documento chamado de "situação do cinema mundial". Nele, Roquette-Pinto, diferenciava o INCE do LUCE através da afirmação de que no congênere italiano o cinema educativo tinha sido prejudicado pelo cinema educativo popular, ou seja, de propaganda.

Em 1943, quando Mussolini é destituído, o LUCE é desmembrado e parte do seu equipamento e pessoal se transfere ao Veneto para trabalhar na República Socialista Italiana (RSI). O INCE, por sua vez, até 1966, seguiu o mesmo ritmo de produção. A saída de Roquette-Pinto, durante os anos 1950, não mudou o ideário educativo do instituto, que foi mantido, em parte, pela permanência de Humberto Mauro. No entanto, como parte de uma estrutura política nacionalista autoritária, o INCE fez filmes de propaganda para o governo de Vargas e seus ministérios. 


\section{UMA COMPARAÇÃO CINEMATOGRÁFICA}

No item que segue realizaremos uma pequena comparação entre as produções cinematográficas educativas do INCE e do LUCE, confrontando escolhas e linguagem cinematográfica. A metodologia empregada se baseia na análise de partes que representam o todo, buscando semelhanças e diferenças em pequenos trechos. O Fascismo e o Estado Novo tinham por objetivo a continuidade de seus projetos nacionais, em que os ideais destes estados estariam presentes ao longo da vida do Brasil e da Itália. Para isto, era preciso educar um "novo homem" que fosse formado segundo os valores sociais e políticos dos estados nacionais-autoritários.

No Brasil, este "novo homem" seria trabalhador, disciplinado, ordenado, consciente de seu papel social, amaria a Pátria e o líder acima de tudo. $\mathrm{Na}$ Itália, os valores eram de coragem, disciplina, ordem, trabalho, sacrifício, força militar e amor ao líder e à Pátria. Neste processo educativo, o cinema surgiu como um grande aliado capaz de divulgar os valores e os hábitos da sociedade fascista e estadonovista, pois as imagens poderiam educar melhor que o livro e o jornal. Um dos recursos adotados no processo de formação do "novo homem" italiano e estadonovista foi a noção da exemplaridade. Segundo Gustavo Capanema, "nenhuma mensagem, nenhuma lição tinha tanta influência educativa como a do exemplo". ${ }^{22}$ Eugenio Ferrauto, educador italiano, também pensava desta forma e considerava importante "oferecer aos pequenos bons exemplos". ${ }^{23} \mathrm{O}$ objetivo era que a vida ou as obras das personalidades históricasnacionais repassassem aos jovens e crianças os valores morais e cívicos dos governos. Desta forma, escolhemos para a análise os filmes de personalidades históricas produzidos pelo INCE e pelo LUCE focando no valor do trabalho, no patriotismo e no sacrifício.

O filme Um Apólogo de Machado de Assis ${ }^{24}$, foi feito em 1939, como parte das comemorações em homenagem ao centenário do escritor. $\mathrm{O}$ filme está dividido em duas partes, uma biográfica e outra teatral, onde se encena o conto A Agulha e a Linha. As primeiras cenas são no morro do Livramento, lugar de nascimento e vida de Machado de Assis. O narrador nos informa o dia e o ano de nascimento do escritor, bem como as profissões de seus pais: seu Francisco era pintor e operário, enquanto dona Leopoldina realizava trabalho doméstico na casa do senhoril. Machado de Assis, comenta a voz em off, antes de ser escritor "foi baleiro, coroinha, tipógrafo, revisor de provas e funcionário público".

Machado de Assis era um exemplo perfeito para crianças e jovens brasileiros, pois havia conquistado o trabalho de funcionário público de forma honesta, ou seja, passando por diferentes profissões ao longo de sua vida. Além disto, seus pais, de profissões humildes e "dignas", haviam ensinado ao filho, 
através de seus exemplos, que o status social e econômico só é alcançado através do trabalho. No Estado Novo o trabalho era visto como um "dever social" em que cada cidadão deveria praticá-lo tendo em vista o crescimento da nação, mais que o pessoal. Podemos dizer que Machado de Assis, ao longo de sua vida de trabalhador, percorreu um caminho de trabalho honesto recompensado ao final com o título de grande escritor brasileiro. Os pais de Machado tem um papel importante nesta narrativa da vida do escritor, pois eles ensinaram ao filho que somente através do trabalho honesto poderia conquistar uma posição social melhor.

O discurso estadonovista de valorização do trabalho afirmava que a maior herança que os pais poderiam deixar a seus filhos era o valor positivo do trabalho, pois somente o trabalho dignificaria o homem. Durante o Estado Novo o trabalho dito honesto estava protegido pela constituição de 1937, o que demonstrava a importância dele dentro da retórica estadonovista. Esta positivação do trabalho estava relacionada com a necessidade de criar um trabalhador dedicado e disciplinado em oposição ao malandro. Desta maneira, o trabalhador se tornava o herói nacional enquanto o malandro era o degenerado, o que causava a desarmonia social dentro da sociedade. Para o trabalhador disciplinado e cumpridor de seu papel o prêmio não seria o dinheiro e sim o status social e a posição de destaque dentro da sociedade estadonovista. Neste sentido, o trabalho ganhava ares de "justiça social", onde os que se dedicassem com afinco e honestidade conquistariam as melhores posições sociais.

Galileu Galilei25 é um filme educativo realizado para a Cinemateca Escolar do LUCE em 1942, a data de produção coincide com a data de morte do astrônomo. Este também é um filme biográfico com ênfase na vida de Galileu Galilei, suas obras e conquistas científicas. O filme começa em um observatório dos anos 1940 com um astrônomo observando o céu. Deste observatório passamos ao século XVII, princípio da história e da vida de Galileu. A passagem é feita através dos olhos de Galileu com a câmera se aproximando de um retrato na parede. Aterrissamos em Pisa, cidade de nascimento e batismo do cientista e onde somos convidados a conhecer os primeiros experimentos e comprovações de Galileu. De Pisa seguimos para Pádua, cidade onde Galileu morou a serviço da República de Veneza. Neste momento, o filme muda o foco, deixa de se concentrar apenas na narração histórica para mostrar que Galileu também é um exemplo para todos.

No tempo em que esteve a serviço do Doge de Veneza, Galileu Galilei aparece no filme como um dedicado trabalhador que não se concentra apenas a investigações intelectuais e sim se dedica à engenharia, inventando e adaptando objetos de uso náutico e militar. Nesta etapa de sua vida, o trabalho manual se sobrepõe ao trabalho intelectual e para o ducado inventa o compasso geométrico militar e o telescópio. Ao falar sobre a invenção do compasso, o narrador 
observa que o objeto foi construído em uma oficina na casa de Galileu. Sobre o telescópio comenta: "Se aplica intensamente em procurar razão e meio para chegar à invenção de um similar instrumento. Mestre também no trabalho com as mãos o reconstrói e o aperfeiçoa". ${ }^{26}$ No filme, a habilidade manual, como o fazer e construir aparece como uma das grandes qualidades de cientista que concilia trabalho manual com intelectual.

No Fascismo, o trabalhador tinha um papel importante de reconstrução da economia de pós-guerra, era preciso fazer com que o trabalho da fábrica e do campo fossem valorizados de forma a aumentar a produção e melhorar a economia interna. Uma forma de fazer isto era manter o trabalhador no campo através da melhoria da vida rural, outra era valorizando o trabalho manual por meio de campanhas sociais e políticas onde o operário e o camponês fossem vistos como o grande motor da sociedade italiana. No entanto, tinham o cuidado de não desprezar o trabalho intelectual, que segundo o discurso fascista, também tinha um papel importante na construção econômica e social. Para o fascismo o trabalho de qualidade era aquele que associava criatividade e atividade manual, valorizando, assim, tanto o esforço intelectual quanto o físico.

No filme sobre a vida de Galileu Galilei esta associação é bastante clara no momento em que fala da construção do telescópio. A voz em off nos faz compreender que o cientista não copiou o invento e sim o transformou, pois "se dedicou a construir algo parecido, ou, melhor". A curiosidade era outra qualidade de Galileu, pois havia se estimulado a construir o objeto depois de ter notícias que um holandês tinha fabricado um par de "óculos" que aproximava coisas distantes. Desta forma, Galileu é um importante exemplo para os jovens fascistas, pois associa trabalho manual e intelectual de forma a produzir algo novo e útil para a sociedade. O narrador não deixa de observar que o invento transformou o modo de navegar da época. A dedicação de Galileu não termina em Veneza. Quando se transfere à Florença, em 1610, Galileu, para assumir o posto de $1^{\circ}$ matemático e filósofo do Grão-ducado da Toscana, passa a desenvolver pesquisas científicas com mais afinco. Ou seja, quando servia aos Doges, preocupados com as navegações, se dedica a inventar objetos e quando se dedica aos duques da Toscana passa a investir nas pesquisas e a escrever livros.

Pensamento e atividade manual empregados em cada momento e a serviço dos interesses dos empregadores. Esta atitude de Galileu combina com o lema dos fascistas para os jovens: Pensiero e azione. Esta pedagogia procurava unir o pensamento à ação, valorizando tanto a ação como o lado intelectual dos jovens. Isto significava dizer que os valores e os ideais fascistas eram apreendidos e depois colocados em ação militarmente. A associação entre o trabalho intelectual e manual era também uma forma de se opor ao capitalismo, que segundo os fascistas, era regido por um trabalho alienante e nada criativo. 
Contando a história de vida e obra de Machado de Assis e de Galileu Galilei, os filmes valorizam o trabalho manual e intelectual das personalidades. No Estado Novo e no Fascismo o trabalho manual e o intelectual tinham o mesmo valor desde que feitos em prol do crescimento da nação. Por outro lado, exaltar o trabalho manual realizado pelas personalidades históricas era uma maneira de retirar o valor negativo que o trabalho manual carregava nas sociedades italiana e brasileira. Por isto a ênfase no trabalho manual de construção que empreendeu Galileu e nos trabalhos de baleiro, tipógrafo e revisor de provas realizados por Machado de Assis.

Ao mesmo tempo em que valorizavam o trabalho com as mãos, os filmes educativos reconheciam o trabalho intelectual do escritor e do cientista. A primeira parte do filme Um Apólogo consiste em apresentar todas as obras escritas por Machado de Assis e também mostra a Academia de Letras como um espaço de memória do passado glorioso do "maior romancista nacional". Ao longo de todo o filme sobre Galileu Galilei os espectadores são apresentados às grandes descobertas astronômicas do cientista. Todas são acompanhadas de palavras que indicam um trabalho de pesquisa e observação incansáveis por parte de Galileu.

Nos dois filmes o trabalho intelectual é visto como um benefício à nação e ao mundo. Galileu, por sua parte, fez descobertas que melhoraram o processo de navegação e fez o mundo pensar diferente com a confirmação de que a terra não era o centro do universo. Machado de Assis, por sua vez, escreveu obras literárias que exaltaram o nome do Brasil e transformaram o mundo literário nacional. Desta forma, ambos os personagens históricos ajudavam a consolidar o conceito de que o trabalho, seja manual ou intelectual, tem que ser feito em prol da coletividade e não do indivíduo.

O "novo homem" do Estado Novo tinha que ser um cidadão orgulhoso da nação e que amasse a Pátria acima de tudo. No caso do Estado Novo o patriotismo funcionava como elemento de agregação, como um "cimento" que une as pessoas em torno do discurso patriótico. Era através das qualidades literárias, históricas, musicais e da natureza do país que o brasileiro poderia se reconhecer como parte de uma mesma nação e sentir amor por ela. Neste sentido, o filme Um Apólogo é uma injeção de patriotismo no coração dos jovens e das crianças brasileiras, pois Machado de Assis contribuiu para o orgulho nacional ao ter sido um grande romancista. Seus romances contavam histórias sobre as relações sociais brasileiras e compunham uma expressão da sociedade real através de uma literatura independente dos modelos estrangeiros. A qualidade dos contos e dos romances de Machado fez com que o Brasil tivesse "um romancista sem igual", como afirma a voz em off no filme. O filme O Barão de Rio Branco, de 1944, é outro exemplo de filme que estimula o patriotismo, pois nele os jovens conhecem todas as conquistas territoriais do 
diplomata. Rio Branco, no filme, é apresentado como um verdadeiro patriota, porque cada passo profissional dado foi feito pensando no bem do Brasil. Por fim, Machado de Assis e Rio Branco conquistam lugares no panteão nacional por conta de suas conquistas coletivas, que elevam o nome do Brasil, e não pelas pessoais. Ou seja, o trabalho é feito em prol da coletividade, da nação e não da conquista individual. O mesmo acontece com Galileu Galilei que elevou o nome da Itália através de suas descobertas e estudos.

No entanto, o orgulho nacional não era uma qualidade tão importante a ser observada pelo "novo homem" do Fascismo, na verdade, a ideia de sacrifício era mais importante que o patriotismo. Galileu Galilei é um símbolo de sacrifício, pois teve que enfrentar a Santa Inquisição e negar a sua teoria em nome de um objetivo maior, seguir investigando e fazendo descobertas. O filme não deixa de narrar o percalço de Galileu com a Igreja que o leva a Roma com o objetivo de explicar a teoria que afirmava que a terra não era o centro do universo. Um pouco de drama acompanha toda a sequência em que o enfrentamento entre o cientista e os representantes do Senhor é contado. Ao acompanharem o sofrimento de Galileu e a sua disposição em negar a teoria para seguir pesquisando e trabalhando, os jovens aprendem que é preciso se sacrificar em nome de um objetivo e que este sacrifício trará a recompensa na hora certa, como anuncia o filme: "mas os séculos lhe darão razão". E o astrônomo passou à história como o mártir da ciência moderna e símbolo do pensamento moderno em oposição ao pensamento mítico-religioso. Os jovens e crianças fascistas eram educados para servirem à Pátria e a lutarem pela Revolução fascista, e, isto, implicava em sacrificar toda uma vida em prol da grandeza da Itália. Não por acaso, durante o Fascismo, foram edificados em toda a Itália monumentos aos soldados mortos na $1^{\text {a }}$ Guerra Mundial, pois eles eram o símbolo do sacrifício feito e a ser feito.

Os filmes de personalidades históricas do INCE e do LUCE apresentam uma linguagem cinematográfica muito parecida em que a história de vida, as obras e os lugares por onde passaram as figuras do passado nacional são apresentadas aos espectadores. Isto nos faz pensar que havia um padrão cinematográfico para fazer um filme educativo, onde o emprego de uma linguagem comum fazia com que o filme fosse visto como educativo pelos seus pares. Os filmes educativos mais do que contar a vida de um personagem tinha que passar valores criando novos hábitos e uma nova maneira de ser e ver o mundo. Esta linguagem cinematográfica educativa comum aponta para uma troca de informação e também por uma busca em se inserir em um universo de fazer cinema educativo.

Ao mesmo tempo, a escolha das personalidades que seriam filmadas era também a escolha de uma história como oficial. Os personagens do passado só eram escolhidos como heróis nacionais e como exemplos se suas vidas e obras 
estimulassem uma relação com o presente. A lista dos filmes de personagens do passado, tanto do INCE como do LUCE, indicam uma relação de aproximação entre passado e presente transformando a história em um objeto de legitimação do presente. $\mathrm{O}$ uso da vida das personalidades desta forma constituía um método de ensino chamado regressivo, em que se buscavam no passado as justificativas para o presente. Tanto o Estado Novo como o Fascismo se consideravam herdeiros do passado e continuadores do passado de glórias. Mussolini era associado constantemente com César, como sendo um continuador de um passado imperial. As escavações arqueológicas davam sentido a este discurso cada vez que revelavam uma Itália grandiosa e imperial romana. A desculpa para atacar a Etiópia e anexá-la ao território italiano estava baseada nos territórios do Império Romano. A história da Unificação italiana ajudava a dar sentido à Revolução fascista através da ideia de construção de uma Itália una e harmônica. No Brasil, este método ajudava a justificar a Revolução de 1930 e o golpe de 1937. Ao estudar a história do Brasil, os alunos se deparariam com a corrupção das oligarquias, com o jogo de revezamento na presidência e com o atraso econômico do país. Desta forma, compreenderiam a missão do novo Estado Nacional. Ao mesmo tempo essa metodologia remetia a um passado negativo, preenchido por pendências políticas e sociais, que eram superadas no presente por Getúlio Vargas. O mesmo acontecia com Mussolini que buscava no passado os erros para justificar sua obra presente.

Considerações finais

O Instituto Nacional de Cinema Educativo, INCE, estava inserido em um contexto internacional, em que o cinema era visto como um veículo de informação e persuasão extrapolando a condição de mero entretenimento. No Brasil, como na Europa, agitavam-se as bandeiras por um cinema moralizado, informativo e educativo, cuja missão principal seria educar pelas imagens. Foi nesta conjuntura de questionamento internacional que o cinema educativo do Brasil foi organizado, buscando na Itália referências para fazer aqui um instituto que correspondesse aos interesses nacionais. Observando as transferências culturais entre os intelectuais brasileiros e italianos, somos capazes de afastar o INCE do projeto nacionalista do governo autoritário de Vargas e inseri-lo em um contexto internacional. Com isto, lançamos um novo olhar ao Instituto Nacional de Cinema Educativo e somos habilitados a analisá-lo de forma comparativa com o Instituto Nacional LUCE, observando suas semelhanças e diferenças sem cairmos nas velhas abordagens que enxergam as instituições do Estado Novo como meras cópias dos fascismos europeus.

A comparação entre os institutos também nos leva a perceber os caminhos que foram seguidos por cada um; um caminho que estava relacionado com a própria realidade política em que os institutos estavam inseridos. Ao 
longo do percurso o LUCE foi tomando um caráter mais de propaganda que de educação e os cinejornais e documentários de propaganda foram tomando conta das produções. Muitos são os motivos que podem explicar a mudança interna do LUCE: a saída de Luciano De Feo e de Paulucci di Calboli, a influência do MINCULPOP, a Guerra da Etiópia e depois a participação na Segunda Guerra Mundial. O INCE desde o começo esteve ligado ao Ministério da Educação e Saúde e isto pode ter contribuído para que os objetivos iniciais não fossem alterados. Por outra parte Roquette-Pinto e Humberto Mauro trabalhavam com certa independência dentro do INCE, o que contribuiu para afastar qualquer tentativa de mudança de planos. Por fim, em 1939 o Departamento de Imprensa e Propaganda (DIP) foi organizado e isto criou dentro do Governo Vargas uma divisão de setor que o LUCE nunca experimentou.

Um olhar comparativo sobre os filmes do INCE e do LUCE nos revelam uma linguagem cinematográfica educativa mundial, onde o fazer cinema estava relacionado com um reconhecer-se como parte do todo. Ou seja, o INCE, apesar de suas particularidades e escolhas relacionadas com o contexto nacional, produzia um tipo de cinema educativo que o colocava em conexão com os outros institutos nacionais de cinema educativo criando assim uma rede de cinema educativo, onde todos buscavam estar inseridos. Fazer cinema educativo não significava apenas divulgar hábitos, valores e conceitos e sim utilizar uma linguagem que o autorizava como tal. Desta forma, comparar a linguagem cinematográfica empregada pelo INCE e pelo LUCE é outra forma de inserir o INCE em um contexto mundial de produção educativa.

\section{NOTAS}

1 A pesquisa foi desenvolvida na Itália com bolsa PDEE - CAPES.

2 O Instituto de Cinematografia Educativa tem por objetivos. Arquivo Gustavo Capanema, GC 35.00.00/1. filme GC 38, CPDOC, FGV.

3 Depoimento de Humberto Mauro ao Museu da Imagem e do Som, em 25 nov. 1966.

${ }^{4}$ Capanema tinha o hábito de se informar e pesquisar o que faziam países europeus em relação à educação e a saúde, a comprovação disto está em seu arquivo depositado na Fundação Getúlio Vargas, no CPDOC, onde encontramos inúmeros folhetos sobre a educação e a saúde em países como Itália e Alemanha e também relatórios informativos.

5 Não existe na Itália, em jornais, revistas ou documentos do Ministério do exterior italiano, qualquer referência a visita de Roquette-Pinto. As informações sobre a viagem foram obtidas no arquivo Roquette-Pinto e no arquivo Gustavo Capanema.

${ }^{6}$ É possível que a partir deste primeiro contato Luciano De Feo tenha passado a enviar a Roquette-Pinto todas as decisões do IICE sobre as questões relativas à produção, exibição, distribuição e circulação de filmes educativos, pois no arquivo do brasileiro encontramos 
diversos documentos com tais informações vindas da Itália. Na revista do IICE não foi encontrado nenhum artigo de Roquette-Pinto.

7 Fundo Jonathas Serrano, caixa 07, pasta 01, Arquivo Nacional. José Roberto de Macedo Soares era encarregado de negócio do Brasil na Itália. A mesma carta também foi encontra no arquivo de Gustavo Capanema.

8 Ibidem.

${ }^{9}$ O primeiro instituto de cinema educativo a ser organizado foi o da União Soviética logo após a Revolução Russa. Também na Suíça existia um instituto de cinema educativo, mas o sistema de cantões existente neste país fez com que o LUCE fosse considerado o primeiro a ser organizado em um Estado capitalista.

${ }^{10}$ TAILLIBERT, Christel. Le Cinéma, instrument de politique extérieure du fascisme italien. In: Mélanges del'école française de Rome. Mefrim, tome 110, 1998 - 2, p. 948.

${ }^{11}$ ESPAGNE, Michel. apud KAELBLE, Harmut. Die Debatte über Vergleich und Transfer und was jetzt? Revista Gêneses, 1994.

${ }^{12}$ Os filmes de caráter educativo-científicos eram "A vida das plantas" e "A circulação do sangue" de Roberto Omegna, conhecido cientista produtor de filmes científicos.

${ }^{13}$ LAURA, Ernesto G. Le stagioni dell 'aquila: Storia dell Istituto Luce. Roma: LUCE, 2004.

${ }^{14} \mathrm{O}$ Instituto de Cinematografia Educativa tem por objetivos. Arquivo Gustavo Capanema, GC 35.00.00/1. Filme GC 38, CPDOC, FGV.

${ }^{15}$ CARVALHO, Francismar Alex Lopes. O conceito de representações coletivas segundo Roger Chartier. Diálogos, v. 9, n. 1, 2005, p. 149.

${ }^{16}$ ROQUETTE-PINTO, Edgar. O Instituto Nacional de Cinema Educativo. Separata da "Revista do Serviço Público", ano VII, v. 1, n. 3, mar. 1944, p. 4. Arquivo Gustavo Capanema, GC 1255, CPDOC, FGV.

${ }^{17}$ SARDI, Alessandro. Cinque Anni di vita dell'Istituto Nazionale LUCE. Novembro 1930. p. 13 Biblioteca Luigi Chiarini, Roma.

${ }^{18}$ Os filmes educativos destinados as escolas eram feitos em $16 \mathrm{~mm}$.

${ }^{19}$ Arquivo G. C., GC 35.00.00/1, CG 38, CPDOC, FGV. Carta é dirigida a Senhora D. Maria Capanema, esposa do ministro. Na carta, a diretora informa que o Banco do Brasil já havia mandado um auxílio de cr\$1050,00, portanto, o que pede é o que falta para completar o valor do projetor.

${ }^{20}$ PCM, 1926, f. 5-1, n. 2830, ACS, Roma.

${ }^{21}$ ROSA, Cristina Souza da. In. Para além das fronteiras nacionais: um estudo comparado entre os institutos de cinema educativo do estado novo e do fascismo (1925-1945). Tese de Doutorado, Instituto de Ciências Humanas e Filosoficas, UFF, Niterói, 2008. p. 117.

${ }^{22}$ Os nossos grandes mortos. Arquivo G. C., GC 35.09.26, filme 35, folha 0002, CPDOC, FGV.

${ }^{23}$ FERRAUTO, Eugenio. Educazione Física nell'educazione giovanile fascista fascista. Parte especifica (scuola ordine elementare) VI esercizi imitativi. Roma: G. B. Paravia E.C., 1940. p. 26. 
${ }^{24}$ Apólogo - Machado de Assis, Um - 1939, p\&b, 35mm, 15 min, sonoro, dir. Humberto Mauro, acervo Funarte-CTAv. Cópia gentilmente cedida à autora pela Funarte-CTAv.

${ }^{25}$ Galileo Galilei-1942, p\&b, 17 min e 50 seg, sonoro, dir. Giovanni Paolucci, acervo Istituto LUCE. Cópia gentilmente cedida à autora pelo Istituto LUCE.

${ }^{26}$ Frase retirada da narração do filme.

Artigo recebido em junho de 2012. Aceito em agosto de 2012. 